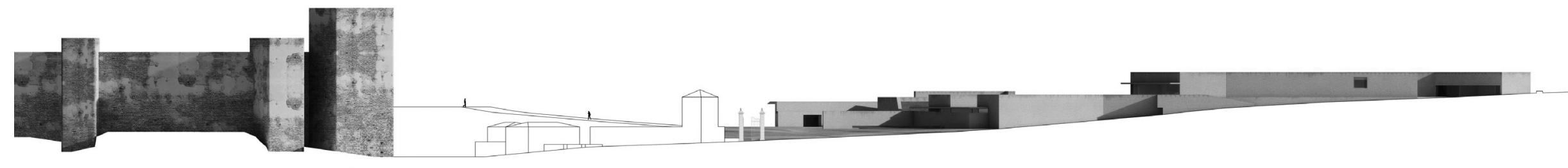

Alzado de la muralla de la Alhambra y perfil del Atrio

\title{
Puerta Nueva. Atrio de la Alhambra
}

\section{Juan Domingo Santos}

Recibido 2015.03.16 :.: Aceptado
DOI: 10.5821/palimpsesto.12.3936

\begin{abstract}
a estructura arquitectónica de la Alhambra es el resultado de superponer una geometría regular sobre un territorio con topografía. En el inicio, la de los palacios Árabes, ortogonal y doméstica, configurada por una secuencia de patios cerrados comunicados entre sí, y más tarde, la del palacio de Carlos $V$, una maravillosa construcción on torno a un patio circular dispuesto sobre la estructura urbana islámica Ambas arquitectures representan la ocupación de un territorio

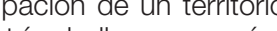
que conviven con el jardín.
\end{abstract}

LaAlhambrano es sólo una experiencia estética, es una arquitectura muy vitalista, un lugar donde la vida se manifiesta en cada rincón y a cada momento a través de la sorprendente fusión entre naturaleza y arquitectura. Un microcosmos de mundos dentro de mundos y de formas recurrentes, donde lo verdaderamente especial es su capacidad para atrapar cosas distintas en el tiempo. El arquitecto Álvaro Siza comenta que la Alhambra encierra una modernidad atemporal que la hace especialmente interesante para el arte y la arquitectura contemporánea.

Históricamente la Alhambra y la creación artística han estado indisolublemente unidos en el tiempo, lo que nos indica que no estamos sólo ante un monumento a conservar fruto de una rica historia de nuestro pasado cultural también es un lugar vivo que sigue interesándonos como espacio de influencia e inspiración para la creación y ta lectura abierta se produce porque el conjunto de la Alhambra no ha sido nunca una arquilectura "acabada" en el sentido de definila o terninada, converida en objeto fosilzado para su conservación. Desde e siglo XVI hasta nustra la evocación, un infinito lugar que se ha reinterpretado a lo largo de la historia de acuerdo a las necesidades de cada momento. En estas circunstancias la visión de la Alhambra puede ser muy amplia, como también muy diferente a ojos de la contemporaneidad, pero aún a pesar de esto, sigue siendo fuente de referencia y modelo en lo que respecta a lo que hay de disciplinar en la arquitectura y de relación con otros campos del arte.
En el año 2010 el Patronato de la Alhambra y el Generalife convocó un concurso internacional de ideas bajo el título "Atrio de la Alhambra". El objetivo del concurso era reformar el área actual de recepción de visitantes y su adaptación a las nuevas necesidades y exigencias del Monumento. La convocatoria planteaba la reordenación de los espacios y servicios actuales con programas que mejoren las condiciones de la visita pública, así como la inserción e integración de una nueva edificación denominada Atrio de la Alhambra que reorganizara las circulaciones y movimientos de los visitantes.

La intervención para el futuro Atrio de la Alhambra es un cúmulo de decisiones sobre lo patrimonial que afecta a la relación entre arquitectura, historia y paisaje. Encierra la difícil tarea del arquitecto de establecer una continuidad libre con la memoria arquitecto de establecer una continuidad libre con la memoria Alhambra se encuadra en un delicado equilibrio entre naturaleza y arquitectura que el tiempo histórico no ha comprometido aún un reencuentro tranquilo con la Historia y su identidad.

\section{Aspectos generales de la intervención}

Son objetivos de la intervención:

1. Ofrecer un espacio preparado para acoger al visitante en unas condiciones adecuadas a este importante patrimonio que satisfaga las necesidades de un amplio espectro de usuarios cada vez más numeroso y resolver la precaria situación que actualmente sufre el visitante que guarda grandes colas a la intemperie, con frío, calor o bajo la lluvia.

2. Entender el proyecto como una reestructuración de los usos y flujos de visitantes a la entrada al Monumento, muy desordenados y sin la calidad suficiente. Reordenar el espacio actual de venta de tickets a través de una solución arquitectónica integrada en el ámbito patrimonial y paisajístico, evitando las actuales colas para la adquisición de tickets y de entrada al recinto.
3. Reorganizar el entorno del edificio Atrio y sus accesos mediante la creación de jardines y paseos previos al recinto amurallado de la Alhambra, mejorando a su vez la accesibilidad a otras edificaciones del entorno como el edificio de los Nuevos Museos.

4. Proponer una nueva edificación Atrio, que contará con un amplio vestíbulo para la venta de tickets y atención al público, servicios complementarios como cafetería-restaurante, la tienda-librería Alen tienda-librín An y administración de la visita. El edilcio se completa con un área cultural con sala de presentación y auditorio para actividades
relacionadas con el Monumento.

5. Eliminar el estacionamiento público en superficie próximo al recinto amurallado, muy impactante, mediante una solución integrada de estacionamiento soterrado que mejore las condiciones actuales, transformando este espacio en un jardín con huertos y zonas de paseo.

6. La intención del Patronato es que las soluciones para el nuevo Atrio sean pioneras respecto a otros monumentos de similares características, convertido en un modelo de referencia por los planteamientos y la calidad de la arquitectura propuesta dentro de un ámbito de indudable valor patrimonial y paisajístico, así como por el sistema de organización de la visita.

El Atrio representa la apuesta por la Alhambra del futuro, la Alhambra del siglo XXI, un paisaje cultural más que un monumento aislado. Un amplio territorio integrador de realidades sociales, culturales, paisajísticas y patrimoniales. Un complejo sistema territorial cuyo núcleo está formado por una ciudad palatina amurallada, rodeada de extensas zonas agrícolas con almunias, áreas de recreo e ingenios hidráulicos. Para interpretar y valorar la importancia de este ámbito que denominamos "territorio Alhambra" se concibe el Atrio, un espacio que ofrece los servicios necesarios para este proyecto de futuro, emplazado entre la visita actual al Monumento y la incursión en su entorno paisajistico.

\section{Puerta Nueva. El Atrio de la Alhambra}

El ámbito de actuación se sitúa extramuros al recinto de la Alhambra, en el espacio que actualmente ocupa el pabellón de venta de tickets, la plataforma del agua, las explanadas de aparcamiento próximas al recinto monumental con la plataforma de desembarco de los autobuses y un conjunto de jardines. Se trata de un ámbito muy desestructurado y en condiciones precarias para acoger al visitante.

Aun siendo difícil la transición entre el espacio construido de la Alhambra y el espacio agrícola inmediato, la solución desemboca en un equilibrio entre el uso y la función, formalizado a través del jardín una propuesta inherente a las características de la propia Alhambra. La estratigrafía arquitectónica muestra que siempre que ha sido necesario ampliar o transformar e Monumento, el jardín ha estado presente como referencia al paisaje. La propuesta del nuevo Atrio es un espacio que relaciona arquitectura y vegetación de forma integrada en un

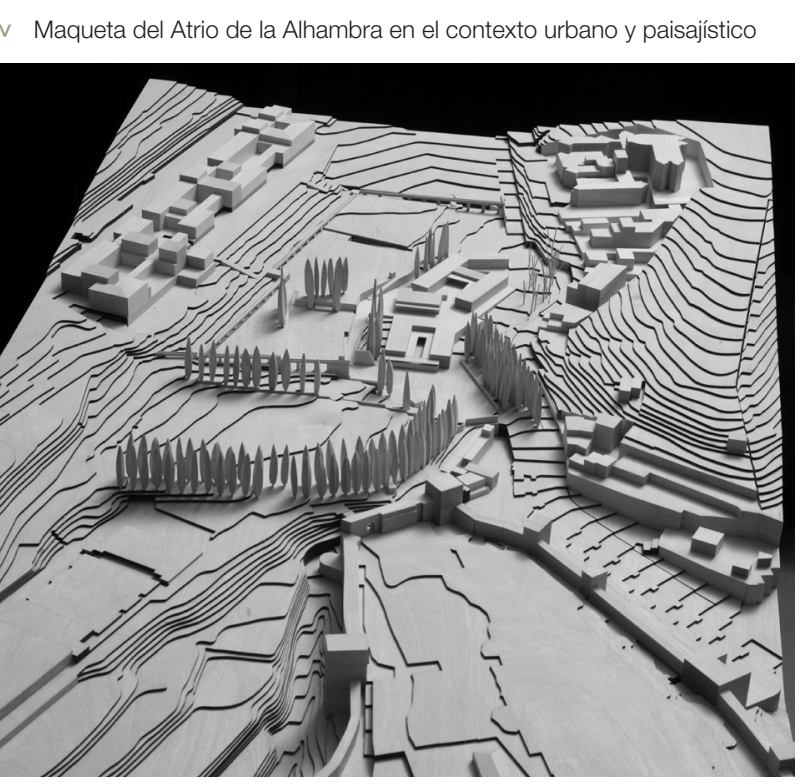


territorio de alto valor paisajístico. La arquitectura se ajusta a la topografía del terreno mediante volúmenes y plataformas en continuidad con los huertos existentes, y se organiza a partir de vistas panorámicas sobre la Alhambra, incorporando preexistencias de interés en el lugar.

El Atrio es la nueva puerta de entrada al Monumento, un espacio de recepción del visitante. Se concibe como un jardín mirador sobre la Alhambra con una secuencia de patios que articulan la

El edificio se organiza compaginando la demanda turística, cultural y de gestión a través de un proyecto que independiza estas tres actividades, evitando posibles intere independiza los usos administrativos y los usos públicos. El espacio cultural queda independiente del Atrio, situado junto a un patio en la plaza de la Alhambra. La organización de la edificación en el territorio responde a un modelo diversificado de usos, lo que ofrece unas mayores prestaciones y un mejor servicio al visitante.

Valores históricos del área de intervención. Preexistencias y elementos de interés

Uno de los trabajos previos ha consistido en identificar visuales

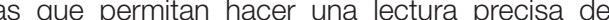
las relaciones con el lugar y que históricamente han tenido un interés especial. La visión de las murallas, la torre del Agua o la puerta de los Siete Suelos, ha determinado la cota de la terraza mirador de llegada y la disposición de los volúmenes.

La propuesta incorpora otras preexistencias como el camino viejo de cipreses que conduce al cementerio o un antiguo muro recubierto de vegetación que cambia de color con las estaciones y al que se articulan los espacios del nuevo Atrio a través de una secuencia de patios, tal y como sucede en las construcciones de los palacios islámicos. El Impluvium, el patio de los cipreses, el patio de yedra y la plaza de la Alhambra construyen una secuencia de lugares de escala distinta. Un muro y una alberca de agua resuelven la transición entre estos cuatro patios antes de acceder al Monumento. A fin de favorecer la permeabilidad entre estos espacios el muro queda suspendido sobre el estanque de agua y se inclina para permitir las vistas de los cipreses del Generalife. La Puerta Nueva es una actuación integral de arquitectura y jardineria.

\section{Terraza mirador sobre la Alhambra}

El Atrio de la Alhambra toma como referencia las plataformas ajardinadas del Generalife, una secuencia de terrazas agrícolas escalonadas sobre el terreno que rodean el espacio exterior del Monumento. Esta imagen de bancales ajardinados extendidos sobre el paisaje permite asociar la arquitectura a un sistema de ocupación natural del territorio, conservando sus perfiles y trazados originales. La arquitectura del Atrio es una sucesión de terrazas en continuidad con los accesos al Monumento construidos a finales de los años 90, un conjunto de huertos y estacionamientos en superficie bajo arbolado con infraestructuras de agua que descienden progresivamente hasta la plaza de la Alhambra, un espacio de transición previo al recinto monumental, libre de construcciones, a fin de permitir la visión de la torre del Agua y las murallas.

La idea de puerta de acceso o entrada al Monumento aparece vinculada a la construcción de un jardín elevado, una plataforma mirador cubierta por pérgolas de glicinia y parra, con albercas de agua bancos y zonas de descanso. Esta terraza mirador se sitúa a la misma altura que los jardines bajos del Generalife e incorpora otras plataformas existentes como zonas de paseo entre huertos de naranjos, cipreses y moreras, sustituyendo el actual aparcamiento en superficie.

\section{Movilidad, programa y usos}

El Atrio se organiza a partir de dos niveles principales relacionados con la cota de llegada de los visitantes. El nivel superior corresponde a la terraza mirador sobre la Alhambra y en torno a ella se articulan los accesos y la entrada principal al edificio. Bajo este nivel se sitúa el gran hall del Atrio, un amplio vestíbulo soterrado a la cota de la plaza de la Alhambra construido en torno a la luz y a un patio de agua (impluvium) que recuerda otros patios como el de la Alberca o Arrayanes. Este vestíbulo se organiza con entradas de luz natural, siguiendo la tradición árabe, creando diferentes atmósferas a partir de la gradación de la luz.

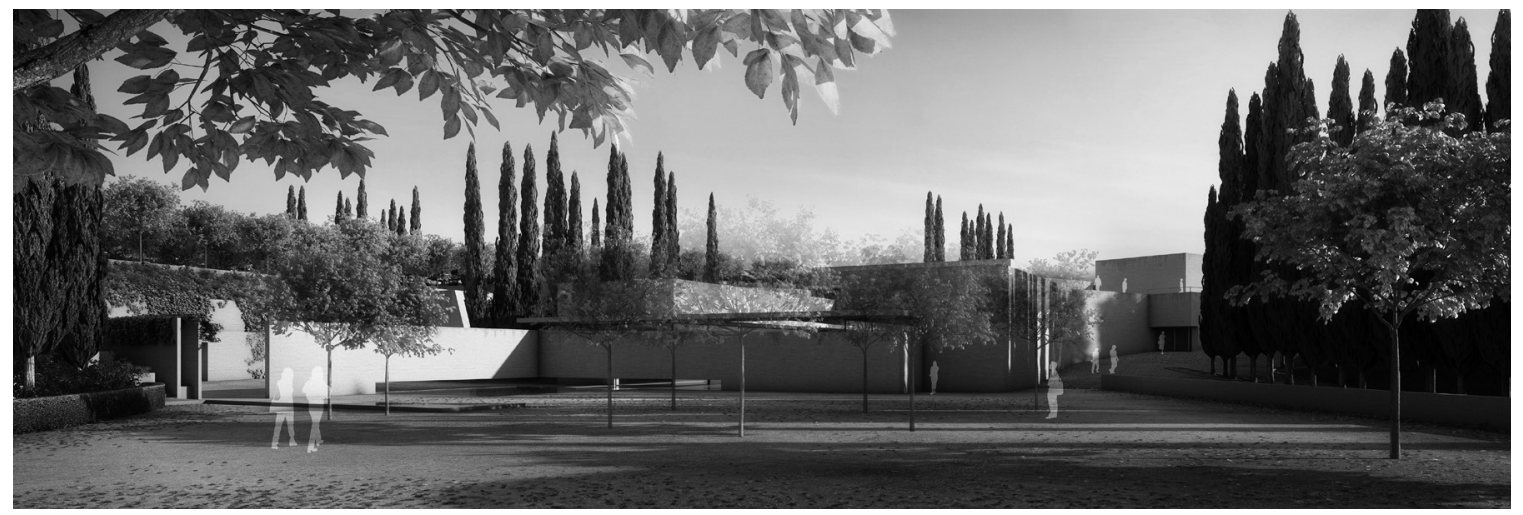

Vla del Atrio desde la plaza Alhambra

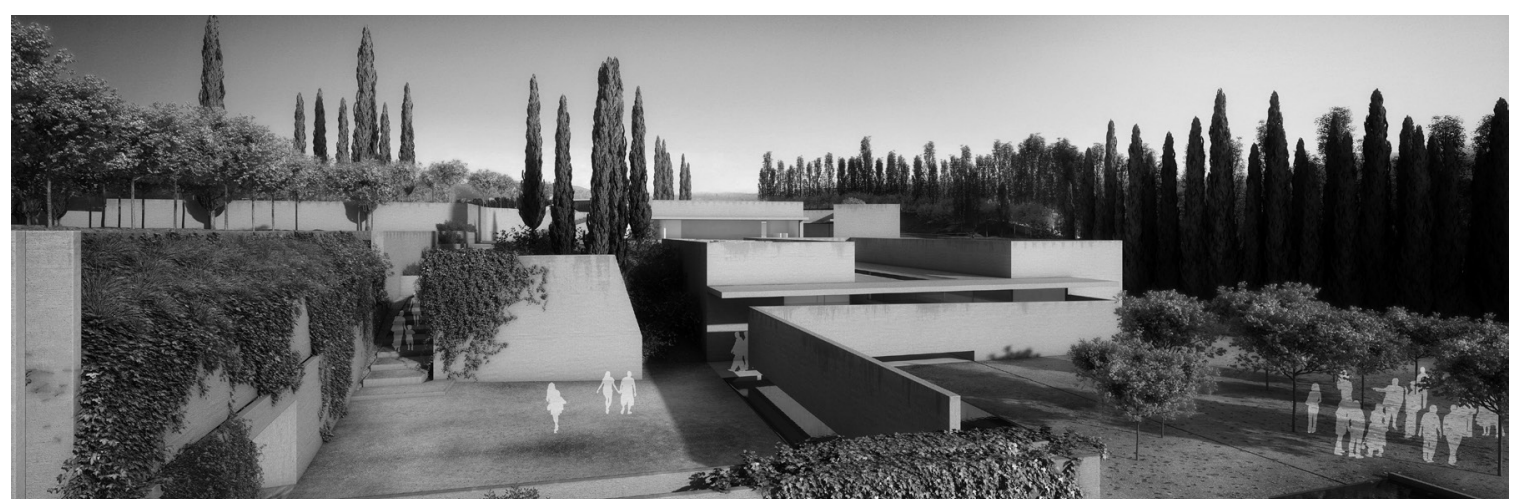

Vista del Atrio de la Alhambra. En primer plano la plaza Alhambra y el patio de ingreso al área cultura

Los programas del Atrio no son nuevos, reorganizan y complementan los ya existentes en este espacio previo a la entrada una estructura de equipamientos distribuidos por el Monumento a fin de mejorar las prestaciones y servicios al visitante. La intención es que el nuevo edificio satisfaga la demanda turística, cultural y de gestión a través de un proyecto flexible y versátil según las necesidades del momento. Contará con espacios para la venta de tickets y atención al público, servicios complementarios como Alhambra, junto a oficinas para la gestión y administración de visita. El programa se completa con un área cultural con de la visita. El programa se completa con un area culto presentación y audtorio, y un parking asterrado para eliminar e superficie junto al Monumento.

Es objetivo prioritario de la intervención reorganizar las diferentes llegadas de visitantes al Atrio: en bus urbano, bus turismo
organizado, taxi, a pie o en automóvil, así como la movilidad organizado, taxi, a pie o en automóvil, así como la movilidad interna dentro del edificio, favoreciendo una solución que evite la concentración de visitantes y un reparto equilibrado por zonas.
Los accesos al edificio se localizan en diversos puntos y por Los accesos al edificio se localizan en diversos puntos y por
niveles, en función de los diferentes itinerarios de llegada del visitante y adaptados a la topografía.

El hall del Atrio

El gran vestíbulo cubierto es la sala principal de operaciones donde el usuario recibe la información y accede a la compra de tickets y servicios para la visita. Se trata de un amplio espacio donde el visitante puede desplazarse con comodidad y sin obstáculos. El objetivo es que este ámbito se organice de manera que no existan colas ni aglomeraciones. El vestíbulo se organiza en torno a un patio central de agua (impluvium).

La iluminación natural del Atrio recuerda la forma de iluminar los espacios en la arquitectura islámica: de la luz intensa del patio, a la luz progresivamente medida y calmada. En el interior, una serie de lucernarios distribuyen la luz cenital en el espacio de manera homogénea.

\section{Plaza de la Alhambra}

Se trata de un espacio arbolado y con agua que articula la relación de la Alhambra con el Atrio, similar a la plaza de los Alijbes junto a la Alcazaba. En la actualidad es un ámbito muy desorganizado que no reúne las condiciones necesarias para la visita. La propuesta convierte este lugar en un espacio previo de espera o reposo antes de acceder al Monumento, con albercas de agua, árboles de sombra (melias y cipreses), bancos para la espera y un nuevo quiosco de bebidas. Es un ámbito preparado para congregar a un gran número de personas, con pavimentos de ladrillo y tierra compactada.

\section{El material. Jardinería, arbolado y pavimentos}

Para la construcción del edificio y su entorno se emplean los materiales y soluciones constructivas tradicionales de la Alhambra: pérgolas con vegetación, pavimentos de empedrado y ladrillo, suelos de tierra compactada (alpañata), patios con albercas de agua, arbolado autóctono y hormigón Alhambra en muros, con acabado en color rojizo. En los acabados interiores mármol y revocos de color blanco para reforzar la luminosidad del espacio. Los lucernarios en el techo introducen una luz matizada al interior del espacio que cambia con el transcurso de día. El mármol y la madera son utilizados para la construcción de algunos elementos singulares como bancos, mostradores y mobiliario

La urbanización y jardinería del conjunto se realiza con arbolado melias y moreras, y plantas tapizantes aromáticas en muros de contención como parra virgen, yedra, jazmín o rosal. En los espacios de sombra y agua se disponen pérgolas de parra y glicinias.

ABSTRACT. El Atrio es un espacio preparado para acoger al visitante a su legada al Monumento en unas condiciones adecuadas a este importante de visitantes de características diferentes y resolver la precaria situación actual que sufre el visitante que guarda grandes colas a la intemperie, con frío, un ámbito muy desestructurado y caótico en la actualidad. La intervención arquitectónica está integrada con la topografía y el entorno, cerrados de la Alhambra. Una arquitectura hecha a partir de los valores de elementos del lugar: pérgolas con vegetación, pavimentos de empedrado y suelos de tierra compactada y de ladrillo, patios con albercas de agua,
arbolado autóctono, hormigón Alhambra en muros y entrada de luz cenital. Palabras clave: Alhambra, Atrio, Puerta Nueva

El proyecto Puerta Nueva. Atrio de la Alhambra es obra de Alvaro Siza Vieira y Juan Domingo Santos. Juan Domingo Santos es arquitecto y profesor de proyectos en la ETSA de Granada.
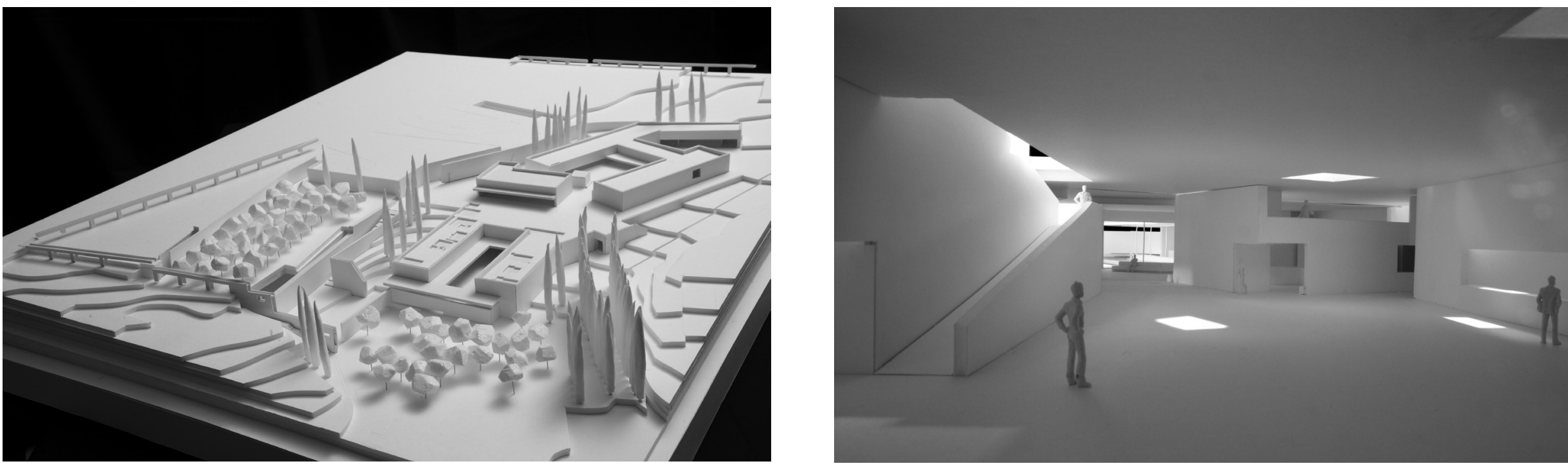